\title{
O PERFUME DA ROSA BENEDITA
}

\author{
THE PERFUME OF ROSA BENEDITA
}

https://orcid.org/0000-0002-3352-2089 Emanuelle Carine da Silva Souza ${ }^{\text {A }}$

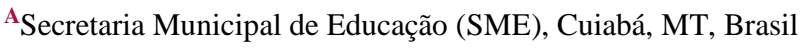

Recebido em: 25 fev. 2021 | Aceito em: 2 set. 2021

Correspondência: Emanuelle Carine da Silva Souza (emanuellecarines@gmail.com)

\section{Resumo}

No artigo em questão, o qual eu defino de modo particular como um relato poético de experiência, apresento a história de Benedita Rosa, mulher preta, quilombola, professora, e mestra, que encontrou na educação um caminho para lutar por sua comunidade e oferecer melhores estratégias para vencer o racismo estrutural, que tanto paralisa a população negra e os acessos á condições melhores de vida. Utilizei de informações passadas pela própria Benedita, bem como uma entrevista sua dada a rede social do Museu de Arte Sacra de Mato Grosso.

Palavras-chave: educação; comunidade quilombola; Mato Grosso.

\begin{abstract}
In the article in question, which I define in a particular way as a poetic report of experience, I present the story of Benedita Rosa, black woman, quilombola, teacher, and master, who found in education a way to fight for her community and offer better strategies to overcome structural racism, which paralyzes the black population and access to better living conditions. I used information provided by Benedita herself, as well as an interview she gave to the social network of the Mato Grosso Museum of Sacred Art.
\end{abstract}

Keywords: education; quilombola community; Mato Grosso. 


\section{Descobrindo os encantos da Rosa}

As rosas sempre me encantaram. Primeiro, porque herdei da minha avó materna - uma mulher preta - o gosto por elas e o cuidado que é preciso ter para que cresçam, floresçam e embelezem onde for que estiverem. Segundo, porque elas coroam grandes momentos, simplesmente por serem quem são e exalarem sua natureza de maneira delicada e extraordinária. E é pensando nelas que escrevo nesse artigo sobre mais uma das rosas que encontrei no meu peregrinar: Benedita.

$\mathrm{Na}$ minha vida toda fui rodeada de grandes mulheres, cada qual a sua maneira. Únicas. E na graduação foi dessa forma também, talvez fazer um curso com predominância feminina tenha contribuído para tal. Mas foi no mestrado, como integrante do Nepre (Núcleo de Estudos e Pesquisa do sobre Relações Raciais e Educação) que nossas histórias se cruzaram,e em 2017, eu me deparo com o perfume de Benedita Rosa.

$\mathrm{Na}$ época, eu tinha iniciado o meu primeiro ano no mestrado e Benedita encontrava-se na finalização do mesmo, com tudo que ele merecia: correria, cansaço, mas muita força de vontade de entregar o melhor. Compartilhávamos a mesma orientadora, Profa. Dra. Candida Soares da Costa, outra mulher preta inesquecível, nossa rosa amarela, e com isso nos encontrávamos com certa frequência, mesmo que de vez em quando se ela ausentasse pelas demandas do quilombo. Sim, Benedita Rosa é quilombola, uma representante importante de sua comunidade, mas falaremos disso mais adiante.

Lembro-me de pensar, quando a ouvi falar pela primeira vez: "que encanto essa mulher tem ao falar". Que docilidade e força ao mesmo tempo. Me encantei. Mas, me encantei mais ainda quando a ouvi falar sobre o quilombo. Ah, tenham essa experiência e ouçam Benedita Rosa falar sobre o quilombo. É como se conseguíssemos transportar para o lugar só de ouvi-la. Ela não fala só com as palavras sobre esse lugar, mas utiliza do seu corpo, da sua história, vivências e memórias para isso.

Enfim, a sua defesa de mestrado foi um espetáculo a parte. Trouxe consigo todas as outras rosas deste jardim, e mostrou para os professores (as) doutores (as) presentes que o quilombo produz conhecimento tanto quanto uma universidade. E que merece estar nesse lugar, não apenas por si, mas para que os outros possam se beneficiar também dessa riqueza e pluralidade. Foi, de fato, um momento inspirador para todos os presentes. O auditório, no dia, teve perfume de Benedita. 
Descrevi acima meus sentimentos ao conhecer Benedita, possuidora de um dos abraços mais acolhedores que já me deparei. Foram por meus olhos. Agora, embora ainda sejam as minhas palavras, será a própria história de Benedita que a descreverá. Uma história de militância, resistência, alegrias e conquistas. Uma história que merece ser contada.

\section{Nasce uma Rosa}

Benedita Rosa da Costa, nascida de parto natural, pelas mãos da parteira "Mãe Miqui", no dia 23 de agosto de 1974, na comunidade rural remanescente de quilombo Tanque do Padre Pinhal, localizado no município de Poconé-MT. Terceira filha no total de cinco filhos do casal Lucinda Leite da Costa e Cristiano Gregório da Costa, e $5^{\circ}$ geração da família de Benedito Pereira Leite, homem preto que fora escravizado.

Benedita nasceu num ambiente, como ela diz, rodeado de mestres e doutores de conhecimentos culturais riquíssimos e sempre muito valorizado. Transmitido de geração em geração, escutando histórias de seus avós, e outros familiares, onde as mesmas eram cercadas de alegrias e tristezas. Ela relata: "essas histórias de alegrias e de tristezas faziam eu chorar porque eu trazia os acontecimentos para o meu contexto e vivências. Idealizava um fato tão próximo de mim! Eu vivia a história! Era um sentimento real na minha vida”.

O seu cotidiano, os pequenos detalhes, inspiravam-lhe por sua beleza: os afazeres domésticos, como varrer a casa, o terreiro, cozinhar, lavar as vasilhas e a roupa, as atividades produtivas como a roça de plantação, a colheita, a fazeção de rede de dormir - desde a fiação, urdição e teceção - a medicina caseira utilizando flores, flores, cascas e raízes das plantas para fazer os chás. As práticas religiosas como a reza do terço, a reza cantada, enfim, a presença forte desses elementos no contexto foram importantes para construir sua identidade quilombola, ao mesmo tempo que fortalecendo sua luta em favor destes, que viria com tempo.

\footnotetext{
Eu afirmo que tive uma infância e adolescência linda, boa, agradável, inesquecível e histórica. Banhei no córrego Piraputanga, pegar bocaiúva na roça, corri e brinquei de esconde- esconde no terreiro e na chapada, brinquei de boneca, de casinha e brinquei de roda em noite de luar. Fui às festas de santos, aniversários e casamentos de familiares e parentes também nas vizinhanças da minha comunidade. (Trecho da entrevista realizada em 28/06/2020)
}

A escola funcionava no terreiro de sua casa. Desde muito cedo, antes de entrar em contato com a educação formal, Benedita teve contato com o mundo dos livros e se apaixonou. 
Antes mesmo de dominar a escrita, já criava histórias com os personagens desses livros, e segundo ela, ficaram bem engraçados. Como sua mãe era professora, sempre lhe cobrou cuidado com os mesmos, e a pequena Benedita Rosa ia crescendo dentro dessa realidade, valorizando-o de maneira muito íntima.

Ao iniciar os estudos, aprendeu rapidamente, levada por sua curiosade, a ler e escrever. Estudou com sua mãe até a $4^{\circ}$ série, em uma sala multisseriada. Diz ela que o método de ensino utilizado era simples e natural: tampa de garrafa, pedrinhas, bocaiúva e outras frutas eram usadas para, por exemplo, estudar as quatro operações matemáticas. Escrevia muitos textos sobre a escola, sobre a roça, as férias, a terra; ou seja, sobre sua realidade.

Continuou os seus estudos na Escola Estadual Juscelino Jubitschek de Oliveira, localizada na periferia de Poconé, no ano de 1986, estudando até o $6^{\circ}$ ano. Em seguida, estudou em outra escola, também estadual, chamada Antônio João Ribeiro até concluir o seu Magistério, no ano de 1993. Contudo, encontrou dificuldades para encontrar uma sala de aula para lecionar, e foi trabalhar de vendedora em uma loja de calçados e posteriormente, na Câmara de Dirigentes Logistas - CDL.

Mesmo encontrando esses desafios, e encontrando em uma área de trabalho diferente, a educação nunca deixou de ter espaço em seu coração e nas suas vontades. Era o seu sonho. Um sonho que se tornou realidade e junto com ele, vários outros que talvez nem soubesse que tivera. E através deles, agora conheceremos o seu jardim.

\section{O jardim}

Como vimos, Benedita Rosa era filha de professora - atualmente sua mãe é aposentada - e desde muito pequena acompanhava sua mãe nas reuniões de professores, e ali já ouvia muito sobre as necessidades da comunidade, sobre a falta de recursos para uma administração escolar que fosse mais efetiva para as crianças da comunidade, ao mesmo tempo em que, mesmo com precariedade, a educação era um caminho importância para todo aquele conhecimento produzido naquele lugar.

Até a $4^{\circ}$ série estudou na comunidade, e depois continuou seus estudos na cidade. $\mathrm{O}$ caminho acadêmico percorrido por ela fez fortalecer a relação entre o quilombo e a educação: se formou em Letras, pela Universidade de Cuiabá. Possui duas especializações: primeira em Ensino de Linguagem pela mesma universidade em que graduou, e a segunda em Educação do Campo: Saberes Pantaneiros e a Socioeconômica Solidária pelo Instituto Federal de Mato 
Grosso. É mestra em Educação pela Universidade Federal de Mato Grosso e, atualmente, é doutoranda em Educação pela mesma universidade. Benedita, em entrevista, fala sobre sua relação com a educação:

\begin{abstract}
Eu sempre vi a necessidade de uma melhoria nas nossas comunidades, na educação, na saúde, na moradia, no esporte, na justiça. Eu sempre acompanhava a minha mãe, que era professora, nos encontros de formação de professores. E nesses encontros eu via as demais lideranças de outras comunidades falando sobre as suas dificuldades, que eram as mesmas dificuldades minha. Eu sempre ouvia esses relatos, essas narrativas. E eu percebi que não era a educação que eu queria para os que vinham depois de mim. Eu estudava numa escola domiciliada, que era rancho, e outras atividades que a gente tinha que fazer, desenvolver tinha que ir para debaixo das árvores. Embora era muito divertido, eu via que era falta de estrutura, falta de investimento do gestor municipal. (Trecho da entrevista realizada em $28 / 06 / 2020)$
\end{abstract}

Suas vivências são tão fortes e presente, fruto também da sua entrega a história e às demandas da comunidade, que fez deste lugar, o seu campo de pesquisa, e dos conhecimentos produzidos nele, o seu objeto. Benedita Rosa, quando questionada sobre sua coleta de dados, diz que os faz desde a infância, já que sua vivência e sua pesquisa se misturam. E em 2017, sua defesa de mestrado teve como título: Comunidade Quilombola Tanque do Padre; Memórias, Narrativas e Vivências. Com isso, Benedita se torna a primeira quilombola a defender uma dissertação no Programa de Pós-graduação em Educação da UFMT. Com toda certeza um marco para o programa, recebera outros quilombolas do mesmo complexo de comunidades.

Além da academia, ela também possui uma caminha ativa na militância sobre as relações raciais e a população quilombola, pensando não somente na educação, mas também nas políticas públicas que envolvem os quilombos. Benedita Rosa diz que, quando a Fundação Cultural Palmares certificou 28 comunidades remanescentes de quilombos em Poconé, se deu conta de que era o momento de pensar políticas específicas para população quilombola. Ela ainda afirma:

\footnotetext{
Entre conferências de educação, estaduais e municipais, audiências públicas, eu participei de todos esses eventos a nível municipal, estadual e nacional. Essa militância me permitiu ser mais conhecedora dos problemas sociais, os fatores que impedem nós quilombolas a termos acesso às políticas públicas, porque tudo que a gente não tem acesso até hoje é responsabilidade dos gestores que, em determinados momentos, ou quase sempre, as políticas não são implementadas conforme a nossa realidade ou não são implementadas como devem ser. (Trecho da entrevista realizada em 28/06/2020)
}

Ela ainda afirma que, ainda existem outras comunidades que estão no processo de certificação e que não há comunidades tituladas ainda. Tais comunidades também apresentam 
variação quanto ao seu modo de origem, sendo muitas delas adquiridas por compra, outras por doações. Existe uma variedade.

Como reflexo dessa militância, foi criada no município uma liderança quilombola formada por diferentes comunidades. Elas fazem diversas atividades, como exemplo, para celebrar o dia 20 de novembro e marcá-la como um dia de celebração e reflexão. Ela diz que em cada ano é comemorado em uma comunidade quilombola do município. Nesta data convidase todas as comunidades e escolas tanto públicas quanto privadas para participarem, além de representantes governamentais.

Aqui Benedita Rosa, como educadora e quilombola, demonstra a importância dessa data, mas também de que uma reflexão tão grande não pode limitar-se a esse dia. É necessário trabalhar essas questões no decorrer do ano, como embasa a Lei 10.639/2003, que alterou a Lei de Diretrizes e Bases da Educação e acrescenta no currículo oficial da Rede de Ensino a obrigatoriedade da presença dos estudos sobre a História e Cultura Afro-Brasileira e Africana. Além disso, existem também as Diretrizes Curriculares Nacionais para a Educação Escolar Quilombola, que segundo ela, devem ser estudadas e cumpridas de acordo com as atividades que são realizadas nas comunidades escolares e nas comunidades ao qual se pertencem. Ela ainda ressalta:

\footnotetext{
Nenhuma das diretrizes nem a lei separam a educação quilombola nem a educação em relações étnico-raciais; ela abrange esses três conceitos da educação, pois não é possível abordá-los de maneira isolada. Por isso se faz o possível para abordar as três questões na escola, já que chegam nas escolas estudantes negros e negras que não são quilombola. (Trecho da entrevista realizada em 28/06/2020)
}

Buscar fazer um trabalho nas escolas com a lei 10.639/03 e a 11.645/08 como um resgate da memória para a construção da identidade quilombola, bem como os conhecimentos produzidos, nunca foi tão urgente e necessário. Colocar a educação quilombola como protagonista, concomitante a educação escolar.

\section{Florescer na Pandemia}

A identidade do povo quilombola passa por uma produção de conhecimento referente a áreas como culinária, agricultura, arte, dança e, também, por medicina natural. E foi, neste último ponto, que Benedita Rosa, juntamente com outros quilombolas da comunidade, resolveram investir na prevenção ao Covid-19, e de outras doenças eventuais. 
Observando a necessidade e a precariedade do serviço público que chega até essas comunidades, foi preciso começar um movimento de informação, prevenção e fortalecimento da imunidade dessa população. Com isso, atrelado ao conhecimento sobre ervas naturais e seus benefícios na saúde, utilizou-se disso como mais um mecanismo de combate nesse tempo de pandemia - claro que junto com as outras medidas já existentes de biossegurança como o isolamento social e a higienização.

Infelizmente, o que Benedita Rosa aponta é que nem todos as comunidades possuem sinal de comunicação para que essas informações cheguem com mais rapidez e eficácia. Contudo, foi um modo que encontrou, juntamente com os demais quilombolas, de continuar produzindo o conhecimento medicinal a partir das ervas plantadas no quilombo, e ao mesmo tempo, contribuir para gerar uma rede de apoio através da saúde dos seus.

\section{Outras rosas do jardim}

Relações baseadas na sinceridade me acompanham pela vida, e na escrita não seria diferente. E por isso preciso começar esse tópico com esta mesma sinceridade. Quando decidi escrever sobre Benedita Rosa, e mergulhei ainda mais na sua história, queria fazê-lo de modo fluido, sem grandes teorias que a escrita científica exigiria, afinal a sua história por si é um registro vivo daquilo que uma estudiosa das Relações Raciais no Brasil já leu por vezes. Contudo, penso que além dela, muitas outras rosas existem nesse jardim que podem ajudar a contar a sua história para que, o leitor que tomar contato com esta produção, possa compreender sua beleza em mais de um aspecto, assim como sua relevância em meio ao cenário atual.

A vivência de Benedita Rosa como diz Santos (2015) traz a dimensão da memória histórica junto com a dimensão do presente da história de luta e resistência dos quilombolas, da sua comunidade e dos antepassados que também resistiram e lutaram para preservar suas riquezas. Conforme a descrição vai acontecendo, é possível se movimentar através de suas memórias e das pessoas que a elas compõem. Um registro importante através da oralidade que agora é transcrita. Esse ponto, particularmente, além de essencial é para mim algo especial.

Como dito anteriormente, através dos discursos apresentados, é possível viajar de maneira delicada e autêntica no seu cotidiano, e não apenas isso, ir contra ao que, desde a época em que os povos africanos foram tirados de sua terra e forçados à escravização pelos portugueses, acontece: a nossa desumanização. Seus pais, seus avós e os que vieram antes deles tem um nome e uma história que Benedita faz questão de contar, e isso marca não apenas a 
humanidade, mas os colocam como produtores de conhecimento e protagonistas de suas histórias.

Assim, o negro africano foi classificado como pertencente a uma raça inferior, destinada à função de servir como escravo. A desumanização do negro não foi um acaso, mas uma consequência perversa das questões econômicas, políticas e culturais em jogo naquele momento e que de certo modo permanecem até nossos dias, visto que o negro, via de regra, continua a ser marginalizado econômica e socialmente, além ainda de estar sob uma sujeição cultural em nossa sociedade, mesmo dentro de uma aparente (e politicamente correta) democracia racial. (REZENDE-SILVA, 2014, p.14)

Ao descrever suas atividades, o plantio, a religiosidade e tudo que acontece no quilombo, pode-se entender que aquele território é preenchido de significações importantes que, transcendem os seus limites quando, por meio da acadêmia, ela produz conhecimento a partir dele. E não apenas isso, mas ao descrever o ganho ao reconhecimento das comunidades como remanescentes de quilombos. Assim, Resende-Silva (2014, p.15) afirma: "as comunidades quilombolas, ao se organizarem pelo direito aos territórios ancestrais, não estão apenas lutando por demarcação de terras, às quais elas têm absoluto direito, mas, sobretudo, estão fazendo valer seu direito a um modo de vida".

A relação de Benedita com a educação também é outro ponto que merece reflexão. As discussões de Paixão (2008), pautadas nas informações sobre a relação existente entre a defasagem escolar e as condições socioeconômicas das crianças e adolescentes dos distintos grupos de raça/cor e sexo no Brasil, a qual demonstra que os problemas da evolução dos estudantes negros no interior da rede de ensino em todo o país, possuíam um componente que transcendia o aspecto meramente social, imbricando-se com vetores reportados às dificuldades intrínsecas do fato de pertencerem àquele determinado grupo racial ou de cor.

Diante do cenário educacional do Brasil, apresentou-se a importância dos estudos das relações raciais como forma de aprofundamento para a criação de estratégias pedagógica para se promover uma educação que inclua negros e brancos dentro de um mesmo espaço, desenvolvendo uma educação que potencialize as forças de cada uma, respeitando as suas particularidades religiosas, culturais e econômicas.

A lei 10.63903 garante que as crianças possam conhecer a sua história dentro do espaço escolar, de perspectivas diferentes daquelas promovidas apenas no dia 20 de novembro. Desfolclorizar o negro e apresentá-lo sujeito social e de história transforma o que poderia ser algo mítico em algo palpável, construindo-se uma percepção de futuro que rompa a linha da reprodução e caminha pela transformação. 
A função social da escola na construção de uma imagem positiva da história da população africana e afro-brasileira é de extrema importância, pois se consideramos que o período escolar também forma pessoas de relações inter e intrapessoais, onde todo os que fazem parte desse ambiente se tornam responsáveis por essa formação subjetiva. Por isso é importante ter uma atitude questionadora diante das relações sociais, de maneira a objetivar a mudança na prática, pois os efeitos sobre os indivíduos e a maneira como irão olhar para um determinado objeto pode fazer toda a diferença nas relações.

E aqui por fim, como pesquisadora negra que também tem a memória como estudo, poder revisitar histórias das quais eu não experienciei, mas pude acessar através das memórias de Benedita Rosa, é de fato um privilégio do qual a mesma nos possibilita. A relação entre o tempo presente e o passado, como nos diz Bosi (1987), permite que a memória guarde experiências únicas de maneira intensa e profunda, mesmo que afetadas pelo tempo.

E para terminar, depois de passaearmos por tão bela história, peço licença para usar as palavras de outra linda Rosa, Conceição Evaristo ${ }^{1}$, para finalizar este artigo - mas não essa história: "O olho do sol batia sobre as roupas do varal e mamãe sorria feliz. Gotículas de água aspergindo a minha vida-menina balançavam ao vento. Pequenas lágrimas dos lençóis. Pedrinhas azuis, pedaços de anil, fiapos de nuvens solitárias caídas do céu eram encontradas ao redor das bacias e tinas das lavagens de roupa. Tudo me causava uma comoção maior. A poesia me visitava e eu nem sabia (...).”

\section{Referências}

BOSI, Ecléa. Memória e Sociedade: lembranças de velhos. 2 ed., São Paulo, T.A. Queiroz: Editora da Universidade de São PAULO, 1987, p. 399.

BRASIL. Lei Federal n. 10.639/2003, de 9 de janeiro de 2003. Altera a Lei n. 9. 394, de 20 de dezembro de 1996, que estabelece as diretrizes e bases da educação nacional, para incluir no currículo oficial da Rede de Ensino a obrigatoriedade da temática "História e Cultura Afro-Brasileira", e dá outras providências. Brasília-DF, 2003. Disponível em: <http://www.planalto.gov.br/ccivil_03/leis/2003/L10.639.htm>. Acesso em: 26 jun. 2020.

BRASIL. Lei Federal n.11645, de 10 de março de 2008. Altera a Lei n. 9.394, de 20 de dezembro de 1996, modificada pela Lei n. 10.639, de 9 de janeiro de 2003, que estabelece

\footnotetext{
${ }^{1}$ Epígrafe' de abertura do livro "Poemas da recordação e outros movimentos". Belo Horizonte: Nandyala, 2008.
} 
as diretrizes e bases da educação nacional, para incluir no currículo oficial da Rede de Ensino a obrigatoriedade de temática "História e Cultura Afro-brasileira e Indígena". Brasília, 2008. Disponível em: <http://www.planalto.gov.br/ccivil_03/_Ato20072010/2008/Lei/L11645.htm>. Acesso em: 26 jun. 2020.

PAIXÃO, Marcelo. A dialética do bom aluno: relações raciais e o sistema educacional brasileiro. Rio de Janeiro: Editora FGV, 2008. 104 p.

RESENDE-SILVA, Simone. Quilombos no Brasil a memória como forma de reinvenção da identidade e territorialidade negra. In: Conflito, Territorialidade e Desenvolvimento: algumas reflexões sobre o campo amapaense. Dourados, MS: Ed. UFGD, 2014. 13-39p.

SANTOS, Antônio Bispo dos. Invasão e Colonização. In: Colonização, Quilombos modos e significados. Brasília. 2015. 